\title{
Advances in Data Envelopment Analysis
}

Celebrating the $40^{\text {th }}$ anniversary of DEA and the $100^{\text {th }}$ anniversary of Professor Abraham Charnes' birthday

\author{
Ali Emrouznejad ${ }^{1 *}$, Rajiv Banker ${ }^{2}$, Luka Neralić $^{3}$ \\ ${ }^{1}$ Aston Business School, Aston University, Birmingham, UK \\ ${ }^{2}$ Fox School of Business and Management, Temple University, Philadelphia, PA 19122, United States \\ ${ }^{3}$ University of Zagreb, Faculty of Economics and Business, Zagreb, Croatia
}

Abraham Charnes was born in Hopewell, Virginia, USA on September 4, 1917, son of Harry and Rebecca Charnes. He died on December 19, 1992 in Austin, Texas at the age of 75. Dr. Charnes graduated in mathematics from the University of Illinois (Urbana-Champaign) in 1938, where he also received a master's degree in mathematics in 1939. After that he received a graduate scholarship to study at Harvard, but this was interrupted by World War II. In 1942 he entered the U. S. Naval Reserve as an Ensign $\mathrm{OV}(\mathrm{S})$ and worked in electromagnetics, torpedo performance and control, supersonic flight, fire control, weapon damage assessment and did the first U. S. pro-submarine operations research. He returned to the University of Illinois where he received a PhD degree in 1947. His dissertation was entitled "Wing-Body Interaction in Linear Supersonic Flow" (adviser D. G. Bourgin). In 1948/49 he began his post-doctoral academic career as an Assistant Professor of Mathematics at Carnegie Institute of Technology. At that time, he married Kathryn Francis and began his lifelong collaboration and friendship with W. W. Cooper. Dr. Charnes also taught at Purdue and Northwestern Universities. At Northwestern he was the Walter P. Murphy Professor of Applied Mathematics. Professor Charnes joined The University of Texas at Austin in 1968. There he held the Jesse H. Jones Professorship and was a University System Professor. He was later named the John P. Harbin Professor in the College of Business Administration. He was also the director of the Center for Cybernetic Studies at the University of Texas at Austin.

Professor Charnes was an internationally recognized mathematician, as well as one of pioneers and great contributors in operations research and management science. His fundamental contributions were in mathematics, statistics, engineering optimization, finance, marketing, and human resource management. He was a founder and president (1960) of The Institute of Management Sciences (TIMS) as well as the editor of Management Science. He was a fellow of the American Association for the Advancement of Science and the Econometric Society. He published 434 journal articles and eight books. He was a

\footnotetext{
* Corresponding author: Ali Emrouznejad, Professor of Business Analytics, Aston Business School, Aston University, Birmingham, UK. Email: a.emrouznejad@aston.ac.uk, Web: www.Emrouznejad.com
} 
finalist for the Nobel prize in 1975. Professor Charnes was the recipient of numerous honors. Among these was the John von Neumann Theory Prize of the TIMS and the Operations Research Society of America (ORSA) in 1982, jointly with W. W. Cooper and R. J. Duffin, for their "fundamental contributions to optimization methods, concepts, and models for problems of decision, planning and design". With Rajiv Banker and W. W. Cooper he received the Notable Contributions to the Governmental Accounting Literature Award from the American Accounting Association. He also received the Harold Lardner Memorial Award from the Canadian Operations Research Society. During the celebration of his sixtieth birthday in 1977, Professor Charnes received the U.S. Navy Medal for Public Service, the Navy's highest civilian award, for his contributions as a research physicist and operations analyst during World War II. In 2006, he was posthumously awarded the Institute for Operations Research and the Management Sciences' IMPACT Prize jointly with W. W. Cooper for all their work on DEA. Professor Charnes is one of only twenty-three individuals to be elected into the International Federation of Operational Research Societies' Hall of Fame as of spring, 2015.

Charnes, Cooper and Rhodes (1978) introduced the basic CCR model of Data Envelopment Analysis (DEA) in their seminal paper "Measuring the Efficiency of Decision Making Units", which was published in the European Journal of Operational Research (EJOR) in 1978. Professor Charnes contributed in DEA as an author or co-author with many published papers in the theory and applications. The CCR model has later been developed further to the BCC model by Banker, Charnes, Cooper (1984). Stability of the CCR model of DEA, proved by Charnes, Cooper, Sears and Zlobec (1990) was very important for applications. He also was an adviser to many students who received $\mathrm{PhD}$ degrees in a variety of areas including DEA.

Professor Charnes was remarkable in many ways: a distinguished scientist, and professor, an adviser, a husband, and father, and a friend, who was ready to help anyone.

Since 1978 there has been continuous and rapid growth in the field of Data Envelopment Analysis. Various DEA models have been developed and employed routinely in areas that range from assessment of public organizations such as educational institutions, health care systems, and governmental bodies to private organizations such as banks, insurance companies and service providers. Currently there are over 10,000 papers published in this area (Emrouznejad and Yang; 2018).

The papers comprising this special issue of the European Journal of Operations Research contribute to the theory and applications of DEA in various areas. The guest editors put together this special issue to celebrate the $40^{\text {th }}$ anniversary of DEA and the $100^{\text {th }}$ anniversary of Professor Abraham Charnes' birthday. This special issue has its origin in the $15^{\text {th }}$ International Conference on Data Envelopment Analysis (DEA2017). The conference was organized by the University of Economics, Prague in the Czech Republic, between June $26^{\text {th }}$ and $29^{\text {th }}, 2017$. The scope of this issue was extended beyond that of 
the papers presented at the conference via an open invitation to the broader academic community working in the area of theory and applications of efficiency and productivity analysis. As a result of the rigorous refereeing process, 15 papers were accepted for inclusion in this special issue. This set of papers represent only a small fraction of the total number of submitted manuscripts but can still offer a wellbalanced mix of topics of DEA in the both theory and application.

The first paper in this issue deals with two-stage estimation of the impact of contextual variables in stochastic frontier production function models using data envelopment analysis. In this paper, Rajiv Banker, Ram Natarajan and Daqun Zhang identify sufficient conditions in a stochastic framework to justify the popular two-stage approach of Data Envelopment Analysis followed by Ordinary Least Squares (DEA + OLS) to estimate the impact of contextual variables on productivity. They show that the effectiveness of the Simar and Wilson's approach critically depends on the assumption that the actual data generating process (DGP) exactly matches their assumed DGP and their approach does not yield correct inferences in environments characterized by stochastic noise. Extensive simulations from a stochastic frontier DGP document that the simple two-stage DEA+OLS model significantly outperforms the more complex Simar and Wilson's model with lower mean absolute deviation (MAD), lower median absolute deviation (MEAD) as well as higher coverage rates when the contextual variables significantly impact productivity. In the same area, Samah Jradi and John Ruggiero in the second paper discuss a quantile regression approach to estimate the production frontier in Stochastic data envelopment analysis. They extend stochastic DEA model of Banker (1988, "Stochastic Data Envelopment Analysis," Working Paper, Carnegie Mellon University) by considering a semi-parametric model that identifies the most likely quantile based on assumptions of the composed error terms. The focus in this paper is on the most common stochastic frontier model with an error structured constrained to a convolution of the normal and half-normal distributions. Using simulated data, this paper compares the model to the econometric stochastic frontier model under different distributional assumptions.

The next paper in this issue is on the benefit-of-the-doubt model with reverse indicators. Rolf Färe, Giannis Karagianni, Maryam Hasannasabd and Dimitris Margaritis reformulate the diet problem as a linear optimization program with desirable and undesirable food nutrients. They then show how the dual formulation of this diet problem is equivalent to a new Benefit-of-the-Doubt $(\mathrm{BoD})$ model with forward and reverse indicators and with a wide range of applications in the construction of composite indicators. The paper illustrates the BoD model to construct a composite index of public health for 180 countries.

The domain of the next two papers is the hyperbolic efficiency measurement. In the first paper Maryam Hasannasab, Dimitris Margaritis, Israfil Roshdi and Paul Rouse transform a hyperbolic distance function into a simple conic programming model. This paper develops a computational procedure for the hyperbolic distance function (HDF) within the nonparametric framework of data envelopment analysis. Authors convert the nonlinear HDF model under variable returns to scale into an equivalent conic 
optimization problem with linear constraints plus a "toppled ice cream" cone constraint that can be efficiently solved by specialized interior point methods in about the same time as a linear program. Applying the dual of an ice cream cone, this paper formulates a multiplier based (dual) HDF model. The paper also elaborates on the structural details of both primal and dual HDF models through geometrical figures. In the second paper, Margaréta Halická and Mária Trnovská discusses that the hyperbolic measure (HM) model is a radial, non-oriented and hence the conventional linear programming methods, customarily used in DEA, cannot be applied to it in general. This paper reformulates the hyperbolic measure model in a semidefinite programming framework which opens the way to solving the HM model by reliable and efficient interior point algorithms. Authors derive the dual of the HM model and so, for the first time, establish its multiplier form. The paper also offers an economic interpretation of the dual HM model via a comparison with the multiplier form of the directional distance model and relate the HM score to the so-called Nerlovian profit efficiency.

The sixth paper in this issue explains the foundation of Charnes, Cooper, and Rhodes definition of the ratio of the virtual output to the virtual input as a measure of the technical efficiency of a multiple output multiple input firm. In this paper, Subhash Ray explains that the aggregation weights used in construction the virtual output and the virtual input may be arbitrarily chosen so long as the weights are non-negative and using these weights no firm's input-output bundle shows efficiency exceeding $100 \%$. In production economics, the ratio of aggregate output to aggregate input is a measure of total factor productivity and a direct link of the CCR ratio to technical efficiency is not obvious. Usually the CCR ratio is rationalized as efficiency by showing its equivalence to the Farrell (1957) efficiency measure. This paper offers a direct derivation of the CCR ratio measure of efficiency from a transformation function. The paper also shows how the $\mathrm{BCC}$ measure under variable returns to scale can be derived from the transformation function.

The next two papers are on the stability regions and improving discriminating power in DEA. In the first paper Luka Neralić and Richard E. Wendell extend fundamental results on metric sensitivity in DEA. Specifically, they show how to obtain a larger radius of stability for a decision-making unit (DMU) by exploiting knowledge about its variability, and how to enlarge a DMU's region of stability to a nonsymmetric hyperbox. In the second paper, Mohammad Reza Ghasemi, Joshua Ignatius, and Babak Rezaee discuss that the lack of discriminating power in efficiency values remain a major contention in the literature of DEA. To overcome this problem, authors explain the super-efficiency model the issue with infeasibility problems under the variable returns-to-scale (VRS). This paper extends the deviation variable form of classical VRS technique and propose a procedure for ranking efficient units based on the deviation variables values framework in both forms - CRS and VRS. With this method, scholars who wish to prescribe theories based on a set of contextual factors need not remove large number of DMUs that are infeasible, thus avoiding problems in generalizability of their findings. 
The next three papers in this issue are on the area of dynamic and network DEA. In the first paper, Francisco J. Santos Arteaga, Madjid Tavana, Debora Di Caprio, and Mehdi Toloo discuss that the dynamic DEA models are built on the idea that single period optimization is not fully appropriate to evaluate the performance of DMUs through time. This paper incorporates two distinct complementary types of sequentially cumulative processes within a dynamic slacks-based measure DEA model. In particular, human capital and knowledge, constituting fundamental intangible inputs, exhibit a cumulative effect that goes beyond the corresponding factor endowment per period. At the same time, carry-over activities between consecutive periods are used to define the pervasive effect that technology and infrastructures have on the productive capacity and efficiency of DMUs. The resulting dynamic DEA model accounts for the evolution of the knowledge accumulation and technological development processes of DMUs when evaluating both their overall and per period efficiency. In the second paper, Juan Aparicio and Magdalena Kapelko extend the measurement of dynamic inefficiency in the full input-output space in the adjustment-cost theory framework to account for slacks. In particular, the paper develops the dynamic weighted additive model in DEA and shows its main properties. In the third paper, Gregory Koronakos, Dimitris Sotiros, and Dimitris K. Despotis reformulate the basic network DEA models using a common modelling framework. This paper shows that the leader-follower approach, the multiplicative and the additive decomposition methods as well as the recently introduced min-max method and the "weak-link" approach, can all be modelled in a multi-objective programming framework, differentiating only in the definition of the overall system efficiency and the solution procedure adopted. Such a common modelling framework makes the direct comparison of the different methodologies possible and enables us to spot and underline their similarities and dissimilarities effectively.

This is followed by a paper authored by Oscar Herrera-Restrepo and Konstantinos Triantis who explain the managerial policies affect enterprise operations facilitating or impeding the achievement of goals. Enterprises can operate individually or might also be part of a group of interconnected enterprises. For an enterprise operating as part of a (de)centralized group of enterprises with a similar or complementary mission and under the same or different ownership, the coordination of decisions and actions is important. Using the concept of network as an arrangement of interconnected nodes, this paper deals with enterprises as the members of a network, and with enterprise transactions as the connections among its members. This paper considers coordination exhibiting connectivity, feedback, and adaptation. These features are not only typical of enterprise networks, but also of complex adaptive systems (CAS). By considering enterprise networks as CAS, authors study managerial policies that affect the coordination among the members of enterprise networks and the subsequent effect on technical efficiency both at the individual member enterprise and network levels. To approximate the effects of coordination-driven managerial policies, they consider flocking behavior from natural ecosystems, which the CAS literature studies, as a proxy for managerial policies. 
Finally, the last two papers in this issue are on the assessment of corporate social responsibility and evaluation of digital government transformation. In the first paper Renata Oliveira, Andreia Zanella, and Ana S. Camanho propose an innovative composite indicator to evaluate Corporate Social Responsibility (CSR). The methodology proposed involves two stages. The first stage specifies an optimization model, based on directional distance functions, to obtain a relative measure of CSR at the firm level that can guide performance improvements. This model allows distinguishing the firms with best practices from those with potential for improvement and can suggest targets for future achievements. In the second stage, a goal programming model is proposed to identify a common set of weights for the key performance indicators, enabling the evaluation of all firms on common grounds. These weights are used to construct an industry ranking, which is based on the distance of firms to a common frontier of technology that respects the trade-offs determined for the industry. In the second paper, Ibrahim H. Osman, Abdel Latef Anouze, Zahir Irani, Habin Lee, Tunç D. Medeni, and Vishanth Weerakkody explain that electronic government services (e-services) involve the delivery of information and services to stakeholders via the Internet, Internet of Things and other non-Internet modes. Despite their beneficial values, the overall level of usage (take-up) remains relatively low compared to traditional modes. They are also challenging to evaluate due to behavioral, economical, political, and technical aspects. The literature lacks a methodology framework to guide the government transformation application to improve both the internal processes of e-services and the institutional transformation to advance relationships with stakeholders. This paper proposes a cognitive analytics management (CAM) framework to implement such transformations. The CAM framework uses cognition to frame the transformation challenge in analytics terms. It conducts benchmarking analysis using DEA to recommend improvement policies. A classification and regression tree is applied to the DEA results to identify characteristics of unsatisfied users to advance relationships.

To conclude, we are grateful to all the authors and to the many reviewers who made this special issue a success. Although it was not possible to include all submitted manuscripts, the editors of this special issue hope that all authors found the feedback helpful for their future work. We also extend our thanks to Professor Robert Dyson, Editor of the European Journal of Operations Research, for giving us the opportunity and for providing full support during preparation of this special issue.

\section{Ali Emrouznejad, Rajiv Banker, Luka Neralić}

February 2019

\section{References}

Banker R. D., A. Charnes and W. W. Cooper (1984). "Some Models for Estimating Technical and Scale Inefficiencies in Data Envelopment Analysis.” Management Science 30(9): 1078-1092.

Charnes A, WW Cooper and EL Rhodes (1978). "Measuring the Efficiency of Decision Making Units.” European Journal of Operations Research 2: 429-444. 
Charnes A., W.W. Cooper, M. Sears, S. Zlobec (1990), Efficiency evaluations in perturbed data envelopment analysis, in: Parametric Optimization and Related Topics II, (J. Guddat, H. Th. Jongen, B. Kummer and F. Nožička, Eds.), Akademie-Verlag, Berlin, 1990, 38-49.

Emrouznejad, A., G. Yang (2018) A survey and analysis of the first 40 years of scholarly literature in DEA: 1978-2016, Socio-Economic Planning Sciences, 61 (1): 4-8.

Farrell, M. J. 1957. The measurement of productive efficiency. Journal of the Royal Statistical Society. 120(3) 253-290. 